\title{
Minimally invasive approach to extraforaminal disc herniations at the lumbosacral junction using an operating microscope: case series and review of the literature
}

\author{
Stephen M. Pirris, M.D., ${ }^{1}$ Sanjay Dhall, M.D., ${ }^{2}$ Praveen V. Mummaneni, M.D., ${ }^{2}$ \\ AND Adam S. KanTER, M.D. ${ }^{1}$ \\ ${ }^{1}$ Department of Neurological Surgery, University of Pittsburgh Medical Center, Pittsburgh, \\ Pennsylvania; ${ }^{2}$ Department of Neurological Surgery, University of California, San Francisco, \\ California
}

Surgical access to extraforaminal lumbar disc herniations is complicated due to the unique anatomical constraints of the region. Minimizing complications during microdiscectomies at the level of L5-S1 in particular remains a challenge. The authors report on a small series of patients and provide a video presentation of a minimally invasive approach to L5-S1 extraforaminal lumbar disc herniations utilizing a tubular retractor with microscopic visualization. (DOI: 10.3171/FOC/2008/25/8/E10)

\section{KEY Words - extraforaminal disc herniation • far lateral disc herniation • lumbosacral junction • minimally invasive spine surgery}

\section{$\mathrm{E}$} XTRAFORAMINAL lumbar disc herniations, otherwise known as far lateral lumbar disc herniations, are relatively rare and comprise $1-12 \%$ of all lumbar disc herniations. ${ }^{1,2,6,10,17,44,46,48,50,54,56,59}$ The approach to an ELDH is more complex than the more common posterolateral or central disc herniation due to an increased risk of postoperative instability from extensive facetectomy, inadequate decompression, or nerve root injury. 5,9,13,18,20,22-24,33,34,41,49,51-53,60 The LSJ is difficult to access due to specific anatomical constraints at this level including compression of the L-5 nerve root by the sacral ala. ${ }^{33,44,47}$ In this report we describe a minimally invasive access for resection of an ELDH at L5-S1 using a muscle-splitting tubular retractor and an operating microscope. Minimally invasive access to ELDHs has been reported previously ${ }^{6,17,33}$ utilizing an endoscopy-assisted approach. ${ }^{4}$ The microscopic visualization described in the present study is more familiar to most spine surgeons and does not hinder the identification of the pertinent anatomical structures.

\section{Methods}

Four patients with symptomatic extraforaminal disc herniations at L5-S1 were included in the study. The operative technique is described below and shown in Video 1.

Abbreviations used in this paper: $\mathrm{ELDH}=$ extraforaminal lumbar disc herniation; LSJ = lumbosacral junction.
Windows Media (broadband):

http://mfile.akamai.com/21490/wmv/digitalwbc.download. akamai.com/21492/wm.digitalsource-na-regional/foc08-

74Pirris_video.asx

After the induction of general endotracheal anesthesia, patients are positioned prone on the operating table with chest bolsters. The lumbosacral region is prepared and draped in sterile fashion. Fluoroscopy is used to identify the medial border of the L-5 transverse process on anteroposterior imaging, and a $3-\mathrm{cm}$ incision is made $1 \mathrm{~cm}$ lateral to this site, allowing the angled trajectory necessary to identify the L5-S1 extraforaminal space safely. Sequential dilators are advanced to create a muscle-splitting corridor for the tubular retractor system, which is secured in place via a table-mounted multiaxis flexible arm (Fig. 1). The operating microscope is positioned over the tube for the remainder of the procedure.

The overlying muscle on the L-5 transverse process is dissected free with a monopolar cautery. Once on bone, the dissection continues inferiorly to expose the lateral pars, facet, and sacral ala. Depending on the anatomical constraints in the individual patient, it is sometimes necessary to drill the superior aspect of the sacral ala to create a functional working space. A Woodson is cautiously used to palpate the neuroforamen and overlying pedicle. A nerve stimulator is used to identify and dissect free the exiting L-5 nerve root, which is gently retracted superiorly to allow visualization of the lateral disc space in its axilla. If necessary, the lateral pars may be resected by using a long, angled drill with a small bur bit. This tool fits easily into an 18- or 22-mm working channel. 


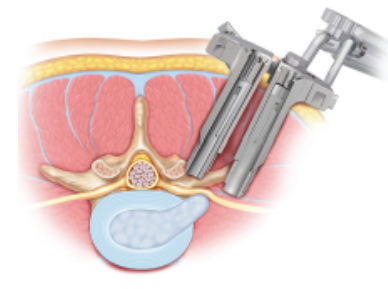

FIG. 1. Artist's depiction of the axial plane of a tubular retractor used for access to the removal of an extraforaminal disc herniation.

The epidural veins are cauterized and sectioned. This maneuver is facilitated by the use of long bayoneted bipolar tips on a low current setting. A down-biting curette is used to remove overlying osteophytes preventing access to the lateral disc space. The annulus is opened in cruciate fashion and traditional microdiscectomy techniques are used to decompress the nerve root. Copious irrigation is performed and meticulous hemostasis is maintained. The tubular retractors are removed allowing the split muscle to return to its native position. The fascia, deep dermis, and skin are closed in routine fashion.

\section{Results}

All 4 patients included in this case series had improvement in their preoperative symptoms and none suffered any perioperative complications. The results are summarized in Table 1.

\section{Discussion}

We describe a method for minimally invasive access to resection of an ELDH at L5-S1 using a muscle-splitting tubular retractor and an operating microscope. This technique adds another option to the surgeon's armamentarium for treating this difficult problem. As noted in previous publications, access to ELDHs is more complex than the more common posterolateral or central disc herniations due to the elevated risk of postoperative instability from an extensive facetectomy, inadequate decompression, or nerve root injury. ${ }^{5,9,13,18,20,22-24,33,34,41,49,51-53,60}$ The overall incidence of ELDH is not known, but has been reported to encompass $1-12 \%$ of symptomatic lumbar disc herniations. ${ }^{1,2,6,10,17,44 \text {, }}$ 46,48,50,54,56,59 The LSJ is difficult to access due to the specific anatomical constraints at this level including compression of the L-5 nerve root by the sacral ala (Fig. 2). . $33,44,47^{2}$

Extraforaminal disc herniations and the associated symptoms due to compression of the exiting nerve root were first described by Macnab ${ }^{37}$ in 1971 in his discussion of negative disc space explorations in patients with radiculopathy. Abdullah and colleagues ${ }^{1}$ then described the clinical syndrome in 1974 which is typically more severe than that caused by the more commonly located posterolateral disc herniations. The "extreme lateral" syndrome described by Abdullah et al. is well characterized and includes marked pain due to involvement of the dorsal root ganglion, with a greater tendency for neurological deficits. ${ }^{11-13,44,46}$ The proximal lumbar levels are more typically involved in ELDHs, ${ }^{2,7,8,14-18,44}$ probably due to the narrower pedicle widths at these levels, which allow for increased disc area in the lateral zone. ${ }^{44,48,59}$ Of all ELDHs reported in the literature, L5-S1 involvement has been reported in
TABLE 1

Summary of results of microscopic minimally invasive L5-S1 extraforaminal discectomies*

\begin{tabular}{|c|c|c|c|c|c|}
\hline \multirow{2}{*}{$\begin{array}{c}\text { Age (yrs), } \\
\text { Sex }\end{array}$} & \multirow{2}{*}{$\begin{array}{l}\text { Compli- } \\
\text { cations }\end{array}$} & \multirow{2}{*}{$\begin{array}{c}\text { Estimated } \\
\text { Blood } \\
\text { Loss }(\mathrm{ml})\end{array}$} & \multicolumn{2}{|c|}{ Prolo Score } & \multirow[b]{2}{*}{$\mathrm{FU}$} \\
\hline & & & Preop & Postop & \\
\hline $58, \mathrm{~F}$ & none & 50 & 10 & 16 & 3 \\
\hline $62, \mathrm{M}$ & none & 50 & 12 & 18 & 11 \\
\hline $57, \mathrm{M}$ & none & 50 & 8 & 20 & 3 \\
\hline $73, \mathrm{M}$ & none & 75 & 8 & 18 & 6 \\
\hline
\end{tabular}

* FU $=$ length of follow-up in weeks.

6.5-25\% of cases since the advent of MR imaging. ${ }^{7,13,19-21 \text {, }}$ $27,35,39,43-46,48,50$

In patients in whom conservative treatment has failed, various surgical approaches have been utilized. Midline incisions with subperiosteal dissections are familiar to most spine surgeons, but often include a significant amount of facet resection, which can lead to postoperative back pain due to destabilization of the motion segment. 14,17,18,20,22-24, 28,29,34,55 The paramedian approach, such as that described by Wiltse and Spencer, ${ }^{61,62}$ requires the splitting of muscles with less bone resection and provides a more direct approach to the neural foramen., $3,17,39,43$ However, this approach is not as familiar to many spine surgeons. ${ }^{17}$ Some surgeons have recommended a combined approach because it permits both medial and lateral access to the neural foramen. ${ }^{8,13-15,28,34,36}$ To obtain adequate visualization of the anatomy for the combined approach, extensive stripping and lateral mobilization of the paraspinal muscles is required, which may lead to increased postoperative pain and paraspinal muscle dysfunction. ${ }^{26,31,32,38,42,57,58}$ The use of percutaneous techniques has been reported, ${ }^{4,30}$ but these are of limited value when free disc fragments and bone compression are present. ${ }^{17}$ The successful removal of free fragments and foraminal stenosis in surgically treated patients with ELDHs has been reported in $72-92 \%$ of patients. ${ }^{2,3,8}$, 14-16,36,39,43

The surgical approach is best guided by the individual

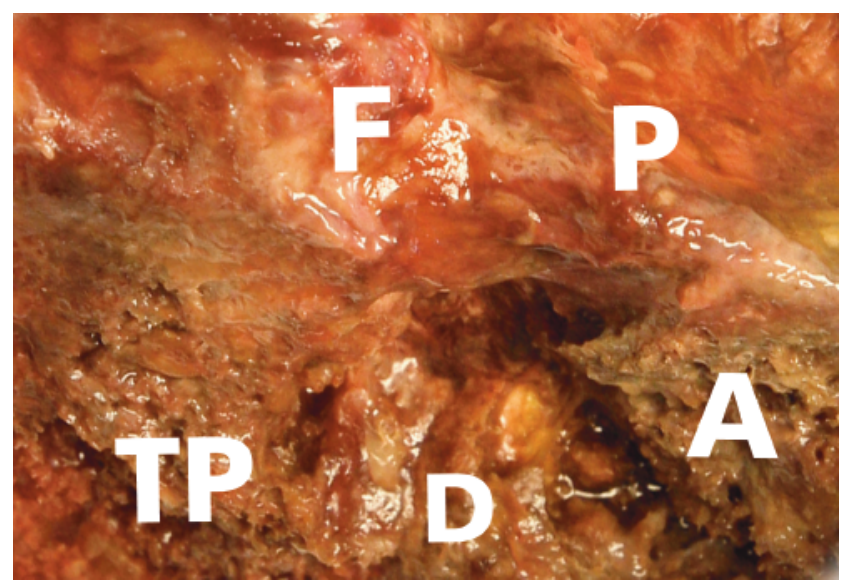

FIG. 2. Photograph of a fresh-frozen human cadaver specimen illustrating the anatomical constraints to the minimally invasive approach to an extraforaminal disc herniation at the LSJ. F = lateral facet of $\mathrm{L}-5 ; \mathrm{P}=$ pars interarticularis of $\mathrm{L}-5 ; \mathrm{A}=$ sacral ala; $\mathrm{D}=$ intervertebral disc at $\mathrm{L} 5-\mathrm{S} 1 ; \mathrm{TP}=$ transverse process of $\mathrm{L}-5$. 
patient's lesion and anatomy. The paramedian approach with muscle splitting generates the least amount of osteoligamentous injury thus limiting postoperative instability. ${ }^{44}$ The anatomy of the LSJ presents unique challenges. Reulen et al. ${ }^{51}$ have described the rigid bone confines of the intertransverse operative corridor, which grows tighter caudally in the lumbar spine secondary to a wider pars interarticularis at L-5, a shorter distance from the caudal transverse process to the superior edge of the inferior articulating process, and a higher frequency of a prominent accessory process. ${ }^{44,51}$ Additionally, difficulty in achieving adequate open posterior or posterolateral access through a midline incision with subperiosteal dissection is created by a prominent iliac crest, wider disc space, oblique pedicles, and more coronally oriented facet joints. ${ }^{44}$

The goals of minimally invasive spinal approaches are to reduce postoperative pain and recovery time while maintaining proper visualization of the important anatomical structures that permit adequate neural decompression. ${ }^{6,16}$, ${ }_{17,44}$ The advantages of the minimally invasive, musclesplitting intertransverse approach to ELDHs include a shortened operative exposure time and with less muscle destruction, preservation of the facet joint, and preservation of surrounding soft tissues, thus reducing the formation of scar tissue. ${ }^{33}$ Additionally, open paramedian approaches to resection of ELDHs require a more lateral to medial approach $^{50}$ which will be limited by the position of the iliac crest for those at L5-S1.

O'Toole and colleagues ${ }^{44}$ reported that the use of progressive dilators and a tubular retractor minimizes the barrier effect of the iliac crest and recommended judicious resection of the sacral ala to allow access to the disc from a lateral approach while avoiding excessive facet resection. ${ }^{25,40,44,48}$ This retractor system is easily adaptable to performing a possible laminotomy in cases where a combined intra- and extraforaminal approach is necessary to completely decompress the nerve root. ${ }^{44}$

The microendoscopic discectomy technique for the treatment of far lateral disc herniations was initially reported by Foley et al. ${ }^{17}$ in a case series of 11 patients. These patients had herniations at L3-4 or L4-5, and all achieved excellent or good results based on Macnab criteria. Cervellini and colleagues ${ }^{6}$ reported on their experience in 17 patients with far lateral disc herniations at L3-4 and L4-5 who underwent surgical treatment with the microendoscopic discectomy technique. All patients achieved excellent or good results. Due to anatomical constraints, the authors claimed that treatment of far lateral disc herniations at the L5-S1 level with this technique is not possible.

Authors of previous reports of minimally invasive access to ELDHs at the LSJ have used endoscopic visualization through the tubular retractor ${ }^{44}$ or microscopic visualization through a self-retaining speculum. ${ }^{33}$ O'Toole et al. ${ }^{44}$ described the far lateral microendoscopic discectomy approach with a $1.8-\mathrm{cm}$ incision. They then used progressive muscle-splitting dilators and placed an 18-mm tubular retractor with an endoscope attached within the tube, and fixed the apparatus in position with a flexible arm. The patient enjoyed immediate pain relief, was discharged home 3 hours postoperatively, recovered his normal gait, and returned to full work and social duties.

Kotil and colleagues ${ }^{33}$ reported on their surgical results in 14 patients with far lateral disc herniations at L5-S1 over a 4-year period. Their minimally invasive intermuscular approach involved a $3-\mathrm{cm}$ transverse incision above the dorsal curvature of the ilium, followed by incision and dissection of the lumbodorsal fascia to retract them from the rim of the ilium. Further exploration was performed with the fingertip to define landmarks such as the transverse process, iliolumbar ligament, lateral edge of the L5-S1 facet, and upper rim of the sacrum with the costal process. Next, a self-retaining speculum was placed and the operating microscope brought into the field. After drilling the costal process of the sacral ala and performing any further bone resection as necessary, the exiting L-5 nerve root was identified and decompressed by discectomy. The outcomes in $13(92 \%)$ of the 14 patients were excellent or good, and the patients were able to return to their previous occupations and activity levels. The 1 patient $(8 \%)$ with a fair outcome was found to have extensive scarring around the nerve root on MR images obtained at the 2-month postoperative examination.

The approach described in this article is a truly minimally invasive approach as described by O'Toole et al. ${ }^{44}$ in that we have used muscle-splitting techniques with progressive dilators through a stab incision in the skin. The primary difference between the 2 is the use of the operating microscope. Most spine surgeons have been trained using the operating microscope and are very familiar with its nuances. The views obtained through endoscopy are undoubtedly exceptional and the purpose of this study is not to dissuade surgeons who are familiar working with the endoscope. However, the use of endoscopy entails an extensive learning curve for the surgeon and operating room staff, occupies some of the working space in the tubular retractor, and incurs a significant expense for the purchase and maintenance of the necessary equipment.

The successful early outcomes obtained in this small series reflect the probable viability of this procedure. Given the small sample size and lack of sustained follow-up, no statistical correlations were calculated. The efficacy of a microdiscectomy for the relief of painful ELDHs at the LSJ has been well documented in the literature. The goal of the present study is to present an effective and truly minimally invasive muscle-splitting approach while utilizing the familiar operating microscope at the L5-S1 level.

\section{Conclusions}

For complex extraforaminal disc herniations at the LSJ, a viable surgical option is to perform the nerve root decompression and discectomy via a minimally invasive, musclesplitting approach with a tubular retractor and operating microscope. The patients in this limited series exhibited initial symptom relief and suffered no intraoperative complications. This approach provides excellent visualization of the pertinent anatomy while utilizing familiar tools.

\section{Disclosure}

Dr. Mummaneni is a paid consultant for DePuy Spine, Inc.

\section{References}

1. Abdullah AF, Ditto EW III, Byrd EB, Williams R: Extreme-lateral lumbar disc herniations. Clinical syndrome and special problems of diagnosis. J Neurosurg 41:229-234, 1974 
2. Abdullah AF, Wolber PG, Warfield JR, Gunadi IK: Surgical management of extreme lateral lumbar disc herniations: review of 138 cases. Neurosurgery 22:648-653, 1988

3. An HS, Vaccaro A, Simeone FA, Balderston RA, O'Neill D: Herniated lumbar disc in patients over the age of fifty. J Spinal Disord 3:143-146, 1990

4. Bonafé A, Tremoulet M, Sabatier J, Boetto S, Docco A, Richardi $\mathrm{G}$, et al: [Foraminal and latero-foraminal hernia. Mid-term results of percutaneous techniques nucleolysis-nucleotomy.] Neurochirurgie 39:110-115, 1993 (Fr)

5. Briggs CA, Chandraraj S: Variations in the lumbosacral ligament and associated changes in the lumbosacral region resulting in compression of the fifth dorsal root ganglion and spinal nerve. Clin Anat 8:339-346, 1995

6. Cervellini P, De Luca GP, Mazzetto M, Colombo F: Micro-endoscopic-discectomy (MED) for far lateral disc herniation in the lumbar spine. Technical note. Acta Neurochir Suppl (Wein) 92:99-101, 2005

7. Darden BV II, Wade JF, Alexander R, Wood KE, Rhyne AL III, Hicks JR: Far lateral disc herniations treated by microscopic fragment excision. Techniques and results. Spine 20:1500-1505, 1995

8. Donaldson WF III, Star MJ, Thorne RP: Surgical treatment for the far lateral herniated lumbar disc. Spine 18:1263-1267, 1993

9. Ebeling U, Reichenberg W, Reulen HJ: Results of microsurgical lumbar discectomy. Review on 485 patients. Acta Neurochir (Wein) 81:45-52, 1986

10. Ehni BL, Benzel EC, Biscup RS: Lumbar discectomy, in Benzel EC (ed): Spine Surgery: Techniques, Complication Avoidance, and Management, ed 2. Philadelphia: Elsevier Science, 2004, Vol 1, pp 609-611

11. Eichholz KM, Hitchon P: Far lateral lumbar disc herniation. Contemp Neurosurg 25:1-5, 2003

12. Epstein NE: Different surgical approaches to far lateral lumbar disc herniations. J Spinal Disord 8:383-394, 1995

13. Epstein NE: Evaluation of varied surgical approaches used in the management of 170 far-lateral lumbar disc herniations: indications and results. J Neurosurg 83:648-656, 1995

14. Epstein NE, Epstein JA, Carras R, Hyman RA: Far lateral lumbar disc herniations and associated structural abnormalities. An evaluation in 60 patients of the comparative value of CT, MRI, and myelo-CT in diagnosis and management. Spine 15:534-539, 1990

15. Faust SE, Ducker TB, VanHassent JA: Lateral lumbar disc herniations. J Spinal Disord 5:97-103, 1992

16. Foley KT, Smith MM: Microendoscopic discectomy. Tech Neurosurg 3:301-307, 1997

17. Foley KT, Smith MM, Rampersaud YR: Microendoscopic approach to far-lateral lumbar disc herniation. Neurosurg Focus 7(5):E5, 1999

18. Garrido E, Connaughton PN: Unilateral facetectomy approach for lateral lumbar disc herniation. J Neurosurg 74:754-756, 1991

19. Gioia G, Mandelli D, Capaccioni B, Randelli F, Tessari L: Surgical treatment of far lateral lumbar disc herniation. Identification of compressed root and discectomy by lateral approach. Spine 24:1952-1957, 1999

20. Godersky JC, Erickson DL, Seljeskog EL: Extreme lateral disc herniation: diagnosis by computed tomographic scanning. Neurosurgery 14:549-552, 1984

21. Greiner-Perth R, Böhm H, Allam Y: A new technique for the treatment of lumbar far lateral disc herniation: technical note and preliminary results. Eur Spine J 12:320-324, 2003

22. Haher TR, O'Brien M, Dryer JW, Nucci R, Zipnick R, Leone DJ: The role of the lumbar facet joints in spinal stability. Identification of alternative paths of loading. Spine 19:2667-2671, 1994

23. Howe JF, Loeser JD, Calvin WH: Mechanosensitivity of dorsal root ganglia and chronically injured axons: a physiological basis for the radicular pain of nerve root compression. Pain 3:25-41, 1977
24. Huber P, Reulen HJ: CT-observations of the intra- and extracanalicular disc herniation. Acta Neurochir (Wein) 100:3-11, 1989

25. Ichihara K, Taguchi T, Hashida T, Ochi Y, Murakami T, Kawai S: The treatment of far-out foraminal stenosis below a lumbosacral transitional vertebra: a report of two cases. J Spinal Disord Tech 17:154-157, 2004

26. Jackson RK: The long-term effects of wide laminectomy for lumbar disc excision. A review of 130 patients. J Bone Joint Surg Br 53:609-616, 1971

27. Jackson RP, Glah JJ: Foraminal and extraforaminal lumbar disc herniation: diagnosis and treatment. Spine 12:577-585, 1987

28. Jane JA, Haworth CS, Broaddus WC, Lee JH, Malik J: A neurosurgical approach to far-lateral disc herniation. Technical note. J Neurosurg 72:143-144, 1990

29. Johnsson KE, Willner S, Johnsson K: Postoperative instability after decompression for lumbar spinal stenosis. Spine 11:107110, 1986

30. Kambin P, O'Brien E, Zhou L, Schaffer JL: Arthroscopic microdiscectomy and selective fragmentectomy. Clin Orthop Relat Res 347:150-167, 1998

31. Kawaguchi Y, Matsui H, Tsuji H: Back muscle injury after posterior lumbar spine surgery. A histologic and enzymatic analysis. Spine 21:941-944, 1996

32. Kawaguchi Y, Yabuki S, Styf J, Olmarker K, Rydevik B, Matsui $\mathrm{H}$, et al: Back muscle injury after posterior lumbar spine surgery. Topographic evaluation of intramuscular pressure and blood flow in the porcine back muscle during surgery. Spine 21:2683-2688, 1996

33. Kotil K, Akcetin M, Bilge T: A minimally invasive transmuscular approach to far-lateral L5-S1 level disc herniations: a prospective study. J Spinal Disord Tech 20:132-138, 2007

34. Kunogi J, Hasue M: Diagnosis and operative treatment of intraforaminal and extraforaminal nerve root compression. Spine 16: 1312-1320, 1991

35. Kurobane Y, Takahashi T, Tajima T, Yamakawa H, Sakamoto T, Sawumi A, et al: Extraforaminal disc herniation. Spine 11:260268,1986

36. Lejeune JP, Hladky JP, Cotten A, Vinchon M, Christiaens JL: Foraminal lumbar disc herniation. Experience with 83 patients. Spine 19:1905-1908, 1994

37. Macnab I: Negative disc exploration. An analysis of the causes of nerve-root involvement in sixty-eight patients. J Bone Joint Surg Am 53:891-903, 1971

38. Macnab I, Cuthbert H, Godfrey C: The incidence of denervation of the sacrospinalis muscles following spine surgery. Spine 2: 294-298, 1977

39. Maroon JC, Kopitnik TA, Schulhof LA, Abla A, Wilberger JE: Diagnosis and microsurgical approach to far-lateral disc herniation in the lumbar spine. J Neurosurg 72:378-382, 1990

40. Matsumoto M, Chiba K, Ishii K, Watanabe K, Nakamura M, Toyama Y: Microendoscopic partial resection of the sacral ala to relieve extraforaminal entrapment of the L-5 spinal nerve at the lumbosacral tunnel. Technical note. J Neurosurg Spine 4:342346, 2006

41. Melvill RL, Baxter BL: The intertransverse approach to extraforaminal disc protrusion in the lumbar spine. Spine 19: 2707-2714, 1994

42. Naylor A: Late results of laminectomy for lumbar disc prolapse. A review after ten to twenty-five years. J Bone Joint Surg Br 56:17-29, 1974

43. O'Hara LJ, Marshall RW: Far lateral lumbar disc herniation. The key to the intertransverse approach. J Bone Joint Surg Br 79: 943-947, 1997

44. O'Toole JE, Eichholz KM, Fessler RG: Minimally invasive far lateral microendoscopic discectomy for extraforaminal disc herniation at the lumbosacral junction: cadaveric dissection and technical case report. Spine J 7:414-421, 2007

45. Osborn AG, Hood RS, Sherry RG, Smoker WR, Harnsberger HR: 
CT/MR spectrum of far lateral and anterior lumbosacral disk herniations. AJNR Am J Neuroradiol 9:775-778, 1988

46. Ozveren MF, Bilge T, Barut S, Eras M: Combined approach for far-lateral lumbar disc herniation. Neurol Med Chir 44:118-123, 2004

47. Perves A, Morvan G: [L5-S1 herniated disk migrated to the anterior part of the right sacral wing with compression of the right lumbosacral roots.] Rev Chir Orthop Reparatrice Appar Mot 82:557-560, 1996 (Fr)

48. Porchet F, Chollet-Bornand A, de Tribolet N: Long-term follow up of patients surgically treated by the far-lateral approach for foraminal and extraforaminal lumbar disc herniations. J Neurosurg 90:59-66, 1999

49. Prolo DJ, Oklund SA, Butcher M: Toward uniformity in evaluating results of lumbar spine operations. A paradigm applied to posterior lumbar interbody fusions. Spine 11:601-606, 1986

50. Quaglietta P, Cassitto D, Corriero AS, Corriero G: Paraspinal approach to the far lateral disc herniations: retrospective study on 42 cases. Acta Neurochir Suppl (Wein) 92:115-119, 2005

51. Reulen HJ, Müller A, Ebeling U: Microsurgical anatomy of the lateral approach to extraforaminal lumbar disc herniations. Neurosurgery 39:345-351, 1996

52. Reulen HJ, Pfaundler S, Ebeling U: The lateral microsurgical approach to the "extracanalicular" lumbar disc herniation. I: a tech nical note. Acta Neurochir (Wein) 84:64-67, 1987

53. Segnarbieux F, Van de Kelft E, Candon E, Bitoun J, Frèrebeau P: Disco-computed tomography in extraforaminal and foraminal lumbar disc herniation: influence on surgical approaches. Neurosurgery 34:643-648, 1994

54. Shao KN, Chen SS, Yen YS, Jen SL, Lee LS: Far lateral lumbar disc herniation. Zhonghua Yi Xue Za Zhi (Taipei) 63:391-398, 2000
55. Shenkin HA, Hash CJ: Spondylolisthesis after multiple bilateral laminectomies and facetectomies for lumbar spondylosis. Followup review. J Neurosurg 50:45-47, 1979

56. Siebner HR, Faulhauer K: Frequency and specific surgical management of far lateral lumbar disc herniations. Acta Neurochir (Wein) 105:124-131, 1990

57. Sihvonen T, Herno A, Paljärvi L, Airaksinen O, Partanen J, Tapaninaho A: Local denervation atrophy of paraspinal muscles in postoperative failed back syndrome. Spine 18:575-581, 1993

58. Styf JR, Willén J: The effects of external compression by three different retractors on pressure in the erector spine muscles during and after posterior lumbar spine surgery in humans. Spine 23: 354-358, 1998

59. Tessitore E, de Tribolet N: Far-lateral lumbar disc herniation: the microsurgical transmuscular approach. Neurosurgery 54:939-942, 2004

60. Wall PD, Devor M: Sensory afferent impulses originate from dorsal root ganglia as well as from the periphery in normal and nerve injured rats. Pain 17:321-339, 1983

61. Wiltse LL: The paraspinal sacrospinalis-splitting approach to the lumbar spine. Clin Orthop Relat Res 91:48-57, 1973

62. Wiltse LL, Spencer CW: New uses and refinements of the paraspinal approach to the lumbar spine. Spine 13:696-706, 1988

Manuscript submitted May 15, 2008.

Accepted May 30, 2008.

Address correspondence to: Stephen M. Pirris, M.D., UPMCDepartment of Neurological Surgery, 200 Lothrop Street, Suite B400, Pittsburgh, Pennsylvania 15213. email: pirrissm@upmc.edu. 